\title{
A comparison of postural and diurnal variations in intraocular pressure using the iCare rebound tonometer and Perkins applanation tonometer in admitted adults in Kenya
}

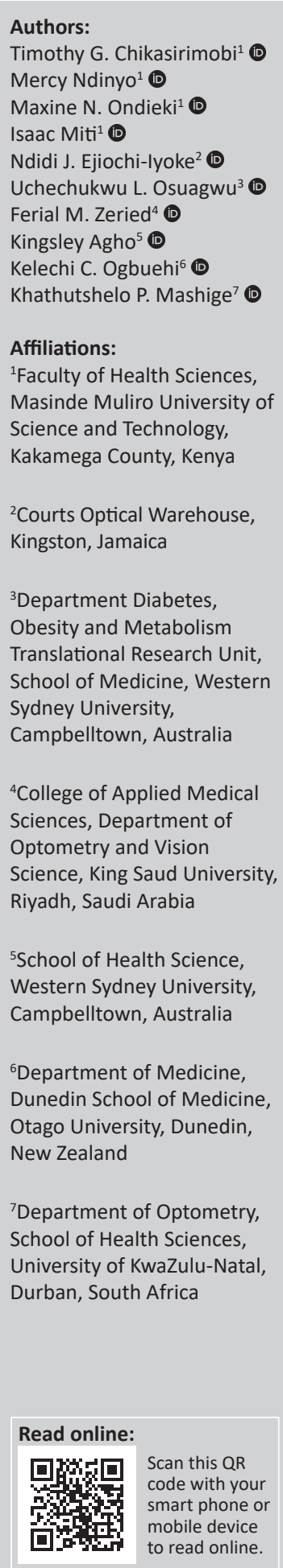

Authors:

Mercy Ndinyo ${ }^{1}$ (1)

Maxine N. Ondieki ${ }^{1}$ (C)

Ferial M. Zeried ${ }^{4}$

Kingsley Agho $^{5}$ (1)

Kelechi C. Ogbuehi 6

Affiliations:

Faculty of Health Sciences,

Science and Technology,

Kakamega County, Kenya

${ }^{2}$ Courts Optical Warehouse,

${ }^{3}$ Department Diabetes, Translational Research Unit, School of Medicine, Western Sydney University,

${ }^{4}$ College of Applied Medical Sciences, Department of

Science, King Saud University,

${ }^{5}$ School of Health Science, Western Sydney University,

${ }^{6}$ Department of Medicine Dunedin School of Medicine, Otago University, Dunedin,

${ }^{7}$ Department of Optometry, School of Health Sciences, University of KwaZulu-Natal, Durban, South Africa

mobile device to read online.
Background: Elevated intraocular pressure (IOP) remained the most important known risk factor for glaucoma.

Aim: To compare the postural and diurnal IOP variations using the iCare rebound tonometer (RT) and Perkins applanation tonometer (PAT).

Setting: Kakamega County Hospital, Kenya.

Methods: Elevated intraocular pressure measurements were taken by two (masked) examiners with two devices in the morning (06:00-09:00), midday (12:00-15:00) and evening (18:00-21:00), in the sitting followed by supine positions in one randomly selected eye of 24 oculo-visual healthy hospital-admitted patients. Effects of the time of the day and position of the body within and between devices were analysed with the Statistical Package for Social Sciences.

Results: The mean IOP measured by the RT ranged from $6 \mathrm{mmHg}$ to 24 millimetres of mercury $(\mathrm{mmHg})$ in the sitting position and from $10 \mathrm{mmHg}$ to $26 \mathrm{mmHg}$ in the supine position. The mean IOP measured using PAT ranged from $6 \mathrm{mmHg}$ to $21 \mathrm{mmHg}$ in the sitting position and from 8 $\mathrm{mmHg}$ to $24 \mathrm{mmHg}$ in the supine position. The IOP measured by both devices significantly varied with position $(p<0.05)$. Perkins applanation tonometer on average gave a significantly higher IOP $(1.7 \mathrm{mmHg}[p=0.003]$ and $1.3 \mathrm{mmHg}[p=0.034])$ at 06:00 compared to that at 12:00 and 18:00, respectively. The IOP readings with the RT were on average $2.2 \mathrm{mmHg}$ and $3.0 \mathrm{mmHg}$ higher at 06:00 compared to that at 12:00 and 18:00, respectively $(p<0.0005)$.

Conclusion: Significant reductions were observed in postural and diurnal IOPs in the sitting positions and in the afternoon, respectively. Diurnal IOP variations were slightly higher when measured by RT compared to when measured by PAT.

Keywords: diurnal variation; iCare; intraocular pressure; Perkins; posture.

\section{Introduction}

Glaucoma has been reported to be the main cause of irreversible blindness and one of the leading causes of blindness worldwide. ${ }^{1}$ Intraocular pressure (IOP) is an important prognostic and the only modifiable risk factor for glaucoma. ${ }^{2}$ The accurate assessment of IOP is, therefore, crucial in the diagnosis and management of this disease, with its traditionally defined normal range being 10 millimetres of mercury $(\mathrm{mmHg})-21 \mathrm{mmHg} .{ }^{2}$ However, a study by Krupin et al. ${ }^{3}$ demonstrated structural and functional damage to the optic nerve (such as increased optic disc cupping, thinning of the neuro-retinal rim and visual field defects) in many glaucoma patients with IOPs within the normal range of $10 \mathrm{mmHg}-21 \mathrm{mmHg}$, suggesting that an elevated IOP is not necessary for the development of optic neuropathy.

Variations in IOP are affected by posture; and in most clinical settings, IOP is usually measured in the sitting position. In general, higher readings are noted in the supine than the sitting position. For example, Gautam et $a{ }^{4}{ }^{4}$ reported that the supine IOP was significantly higher compared to the

Corresponding author: Khathutshelo Mashige, mashigek@ukzn.ac.za

Dates: Received: 19 Sept. 2020|Accepted: 26 Feb. 2021|Published: 17 May 2021

How to cite this article: Chikasirimobi TG, Ndinyo M, Ondieki MN, et al. A comparison of postural and diurnal variations in intraocular pressure using the iCare rebound tonometer and Perkins applanation tonometer in admitted adults in Kenya. Afr Vision Eye Health. 2021;80(1), a617. https://doi.org/10.4102/aveh.v80i1.617

Copyright: ๑ 2021. The Author(s). Licensee: AOSIS. This work is licensed under the Creative Commons Attribution License 
sitting IOP, at all times of the day, in patients with untreated glaucoma, glaucoma suspects and healthy volunteers $(p<$ 0.001). This postural IOP variation pattern is believed to be because of an increase in the episcleral venous pressure. ${ }^{5}$

Variations in IOP are also observed over the course of the day; IOP is high on awakening and keeps reducing throughout the day, reaching the lowest level in the early evening. ${ }^{6}$ Research has suggested that this may be related to the reduced production of aqueous humour at night. ${ }^{7}$ Arora et $a .^{6}$ evaluated the role of measuring IOP outside office hours in primary, adult-onset glaucoma and reported that $66 \%$ of patients had maximum IOP readings during this time, with the mean diurnal fluctuation $(7.03 \mathrm{mmHg} \pm 2.69 \mathrm{mmHg})$ being significantly higher than the mean office fluctuation $(4.31 \mathrm{mmHg} \pm 2.6 \mathrm{mmHg})(p<0.01)$. The authors ${ }^{6}$ concluded that diurnal monitoring may be particularly useful in patients with high baseline IOP readings. However, other reports show that some individuals reach their peak IOP in the afternoon or evening whilst others follow no consistent pattern. 8,9

Studies on the importance of detecting IOP fluctuations and peak measurements on the risk of glaucoma development, its progression and management have yielded conflicting results. For example, some studies have reported that large diurnal and postural fluctuations in IOP are potential independent risk factors for the progression of glaucomatous optic neuropathy ${ }^{10,11}$ whilst others found no such association. ${ }^{12,13}$

The Perkins applanation tonometer (PAT) is a handheld device that works on the same principle as the Goldmann applanation tonometer (GAT). Arora et al. ${ }^{14}$ reported that PAT yields IOP measurements that are sufficiently comparable to the GAT to be acceptable for routine clinical practice. The iCare rebound tonometer (RT) uses rebound technology and involves an analysis of the rebound motion of the device probe after interacting with the anterior surface of the cornea. ${ }^{15}$ The RT is a widely used handheld IOP screening tool, particularly in primary care settings, but the evidence of its comparability with GAT is not conclusive. For example, studies have shown that RT measurements compared reasonably with the GAT ${ }^{16,17}$ with at least one recent report suggesting that it overestimates IOP. ${ }^{15}$

Several studies of the diurnal and postural variations in IOP using different devices have been conducted, which yielded different and contradictory results for a variety of reasons. ${ }^{18,19}$ Although there is a clear evidence of IOP fluctuations over the course of the day, it is commonly based on isolated measurements in the sitting position during office hours visit. It is, therefore, possible that the IOP peak and fluctuations may be missed during office hours. The objective of the study was to compare the diurnal and postural IOP variations in healthy adults using the RT and PAT. This study will help eye care practitioners understand the trend of fluctuations in IOP as it relates to position, time and technique.

\section{Methods}

This observational, cross-sectional study used a random sampling technique to determine the eligibility of patients aged 40 years and older admitted to the men and women's medical wards of Kakamega County Teaching and Referral Hospital (KCTRH), for 3-5 days. This study adhered to the tenets of the Declaration of Helsinki, and ethical approval was obtained from the institutional review board of Masinde Muliro University of Science and Technology. Written informed consent was obtained from all patients after a detailed explanation of the study and examination. Using the $G^{*}$ power software, the sample size for this study was calculated based on the average values of IOP obtained with PAT to warrant a power of $80 \%$ with a statistical significance level of 0.05 . The minimum sample size was calculated to be 23 .

The exclusion criteria were IOPs recorded during normal clinic hours (10:00-16:00), which exceeded $21 \mathrm{mmHg}$; another ocular or systemic disease that could damage the optic disc; taking corticosteroids, which can increase IOP; patients who had undergone a previous ocular surgery and patients who had a corneal abnormality that prevented reliable IOP measurement.

Only patients who were oculovisually healthy during the study period were included, and all participants maintained their normal sleep and wake hospital schedule without restrictions. The IOP was measured with both a portable or mobile RT (Tiolat, Helsinki, Finland) and PAT (Haag-Streit). For IOP measurements with the RT, the patient was requested to look straight at the fixation target, and the tonometer was brought closer to the patient's eye. The software of the iCare ${ }^{\circledR}$ instrument is designed for six automatic consecutive measurements, with the output being the mean pressure and standard deviation, with the average value being displayed on the digital screen and recorded as the IOP. If a faulty measurement is obtained, it is automatically discarded by the software.

For contact IOP measurements, PAT was used, and its calibration was checked at the beginning of each session, according to the manufacturer's instructions. Topical anaesthesia was applied, and the eyes were dabbed to remove excess fluid from the ocular surface, with the applanation being performed three times and averaged by the one examiner. All IOP measurements with both devices were carried out three times a day in the sitting and supine positions. Both the sitting and supine position measurements were taken after the patient had been in the position for 30 min, with the patient looking straight ahead. The diurnal IOP was the result of these sitting and supine IOPs which were carried out three times a day: in the morning (06:00-09:00), midday (12:00-15:00) and evening (18:00-21:00). Two examiners obtained the measurements in a masked fashion (one with RT in both positions and another with PAT in both positions), and a research assistant recorded the results each time. Results were read out by the examiner who obtained the measurements whilst the research assistant recorded them and imported the data into an Excel spreadsheet. 


\section{Statistical analysis}

All statistical analyses were performed using the Statistical Package for Social Sciences (SPSS, IBM NY) version 25. Continuous data were summarised using descriptive statistics including the mean, standard deviation (s.d.), minimum and maximum iCare RT and PAT values in each session and with each technique. The dependent variables (PAT and RT IOPs) were normally distributed and $t$-tests were used to compare significant differences between groups for each time whilst the analysis of covariance (ANCOVA) test was used for between-group analysis; the differences were considered significant at $p<0.05$. The analysis entailed establishing any differences for each position with respect to the time of the day and between two positions during the day.

The mean differences in IOPs (calculated by the differences in IOPs between three time points) were plotted against the mean IOP values for the same position. This was to show the pattern of diurnal variation in IOP for each position using each device. Bland-Altman plots were used to show the limits of agreement (LoAs) for the methods. For these graphs, the mean difference in IOP (PAT minus RT) was derived for the same position and at the same time and plotted as a function of average IOPs. The 95\% confidence intervals (CIs) were also shown. This was necessary to indicate whether both the tonometers can be used interchangeably for clinical assessment of IOPs at any position and/or at any time point during the day.

\section{Ethical considerations}

This study adhered to the tenets of the Declaration of Helsinki, and ethical approval was obtained from the institutional review board of Masinde Muliro University of Science and Technology (MMUST/IERC/50/19). Written informed consent was obtained from all patients after a detailed explanation of the study and examinations.

\section{Results}

Of the 30 patients who were approached to participate, 5 declined and one dropped out, with data being collected from 24 participants ( 7 women, $29.2 \%$ and 17 men, $70.8 \%$ ) aged $48.3 \pm$ 7.0 years (range, 40-62 years). With respect to the IOP measurements obtained from the 24 participants, the comparative analysis of two methods showed values ranging from $6 \mathrm{mmHg}$ to $21 \mathrm{mmHg}$ using PAT in the sitting position, and from $8 \mathrm{mmHg}$ to $24 \mathrm{mmHg}$ in the supine position. The RT sitting position results ranged from $6 \mathrm{mmHg}$ to $24 \mathrm{mmHg}$ and that of the supine position from $10 \mathrm{mmHg}$ to $26 \mathrm{mmHg}$. Table 1 shows the average ( \pm s.d.) and range of readings for IOP obtained from the two techniques in both positions and all three sessions. On average, the RT showed the highest mean values for IOP, higher than those obtained in the supine position, followed very closely by PAT in the supine position. The lowest mean values were observed for PAT in the sitting position.

The ANCOVA results revealed no significant effect of position on PAT IOP measurement at the sitting position;
TABLE 1: Averages, standard deviations and intraocular pressure ranges $(\mathrm{mmHg})$ with the two devices.

\begin{tabular}{|c|c|c|c|c|c|c|c|c|c|}
\hline \multirow{2}{*}{$\begin{array}{l}\text { Intraocular } \\
\text { pressure (mmHg) } \\
\text { Positions }\end{array}$} & \multirow[t]{2}{*}{ Times } & \multicolumn{4}{|c|}{ Perkins applanation $* * *$} & \multicolumn{4}{|c|}{ iCare rebound $* * *, * * * *$} \\
\hline & & Mean & s.d. & Min & Max & Mean & s.d. & Min & Max \\
\hline \multirow[t]{3}{*}{ Sitting } & 06:00-09:00 & 13.4 & 3.2 & 8 & 21 & 16.4 & 3.0 & 9 & 24 \\
\hline & $12: 00-15: 00$ & 12.2 & 2.7 & 6 & 18 & 14.1 & 2.5 & 6 & 19 \\
\hline & $18: 00-21: 00$ & 13.1 & 3.1 & 7 & 19 & 14.2 & 2.7 & 8 & 19 \\
\hline \multirow[t]{3}{*}{ Supine } & 06:00-09:00 & 16.6 & 3.3 & 11 & 24 & 18.0 & 3.9 & 12 & 26 \\
\hline & $12: 00-15: 00$ & 14.4 & 2.8 & 11 & 20 & 16.0 & 3.4 & 10 & 25 \\
\hline & $18: 00-21: 00$ & 14.3 & 2.9 & 8 & 20 & 16.0 & 3.2 & 11 & 21 \\
\hline
\end{tabular}

Note: No significant association was found between time and position for both the devices $(p>0.05) . P$-values are results of ANCOVA for effect of time and position for each device.

s.d., standard deviatio; Min, minimum; Max, maximum; $\mathrm{mmHg}$, millimetre of mercury.

$*, 0.262$;* $0.126 ; * * * 0.008 ; * * * *<0.0005$.

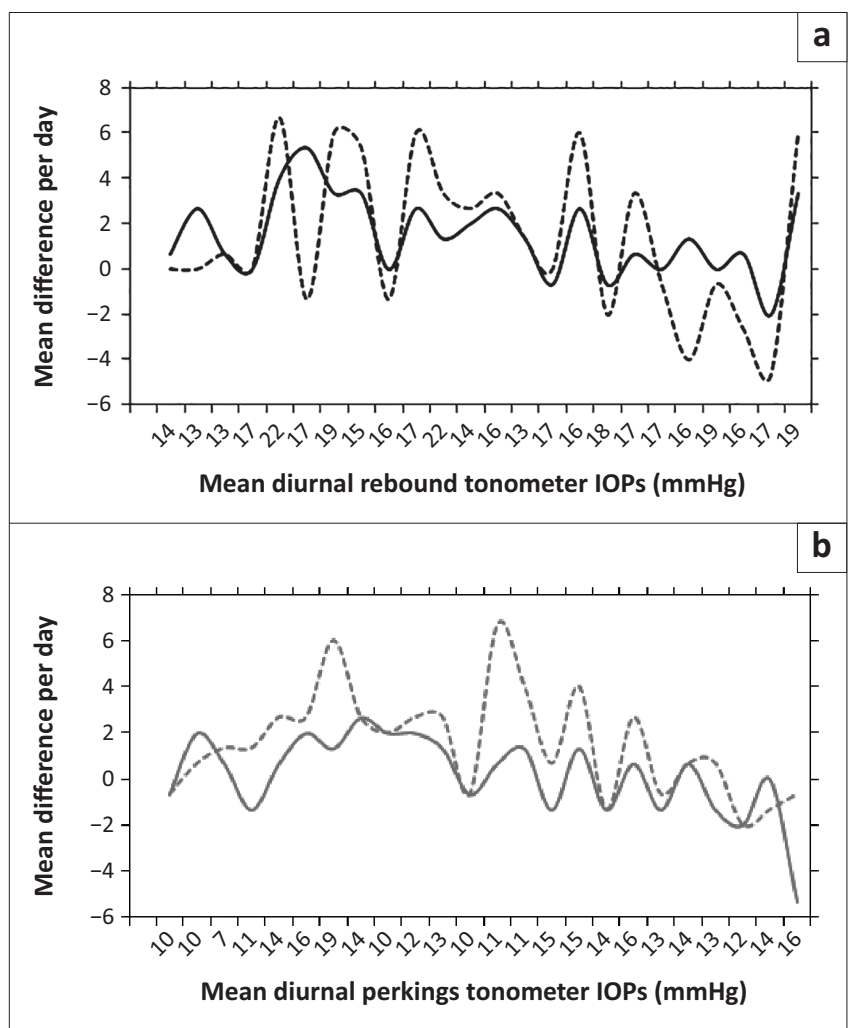

$\mathrm{IOP}$, intraocular pressure; $\mathrm{mmHg}$, millimetre of mercury.

FIGURE 1: Mean difference in intraocular pressure variations between devices. Dotted and solid lines are differences in measurements obtained in supine and sitting positions, respectively.

however, posthoc analysis showed differences between time points. Perkins applanation tonometer IOPs were on average $1.7 \mathrm{mmHg}(95 \% \mathrm{CI}$ of mean difference $=0.7 \mathrm{mmHg}-2.8 \mathrm{mmHg}$, $p=0.003)$ and $1.3 \mathrm{mmHg}(95 \% \mathrm{CI}$ of mean difference $=0.1-2.4$ $\mathrm{mmHg}, p=0.034$ ) higher at 06:00 compared to that at 12:00 and 18:00, respectively. By contrast, the RT readings were significantly affected by time, returning on average $2.2 \mathrm{mmHg}$ (95\% CI of mean difference $=1.1 \mathrm{mmHg}-3.2 \mathrm{mmHg}$, $p<0.0005)$ and $3.0 \mathrm{mmHg}(95 \% \mathrm{CI}$ of mean difference $=$ $1.7 \mathrm{mmHg}-4.2 \mathrm{mmHg}, p<0.0005)$ higher IOP readings at 06:00 compared to that at 12:00-15:00 and 18:00-21:00, respectively. Figure $1 \mathrm{a}$ and $\mathrm{b}$ shows the difference in IOP measurements between three time points (variation) for the two devices. Comparing devices, the diurnal IOP variation was found to be significantly different between PAT and RT, with latter readings being higher in both positions. 
The limits of repeatability (LoRs) for PAT-IOP in the sitting position were $0.2 \mathrm{mmHg}$ (95\% LoRs: $-3.3 \mathrm{mmHg}$ to $3.7 \mathrm{mmHg})$ and $1.5 \mathrm{mmHg}(-2.9 \mathrm{mmHg}$ to $6.0 \mathrm{mmHg})$ in the supine position. For RT, the corresponding values were $1.5 \mathrm{mmHg}(-2.0 \mathrm{mmHg}$ to $4.9 \mathrm{mmHg})$ and $1.4 \mathrm{mmHg}$ $(-5.3 \mathrm{mmHg}$ to $8.1 \mathrm{mmHg})$, respectively. The mean IOP was measured slightly higher by RT than by PAT in the initial sitting position, with the $95 \%$ LoAs varying from -7.9 to 1.9 , -7.00 to 3.00 and $-6.2 \mathrm{mmHg}$ to $4.2 \mathrm{mmHg}$ in the morning, afternoon and evening, respectively (Figure 2).

The IOP readings of the participants in the supine position were found to be higher for both techniques than those obtained in the sitting position. The $95 \%$ LoAs between the two devices in the supine position were $-8.1 \mathrm{mmHg}$ and $5.3 \mathrm{mmHg},-8.8 \mathrm{mmHg}$ and $6.0 \mathrm{mmHg}$ and $-7.0 \mathrm{mmHg}$ and $3.0 \mathrm{mmHg}$ in the morning, afternoon and evening, respectively.
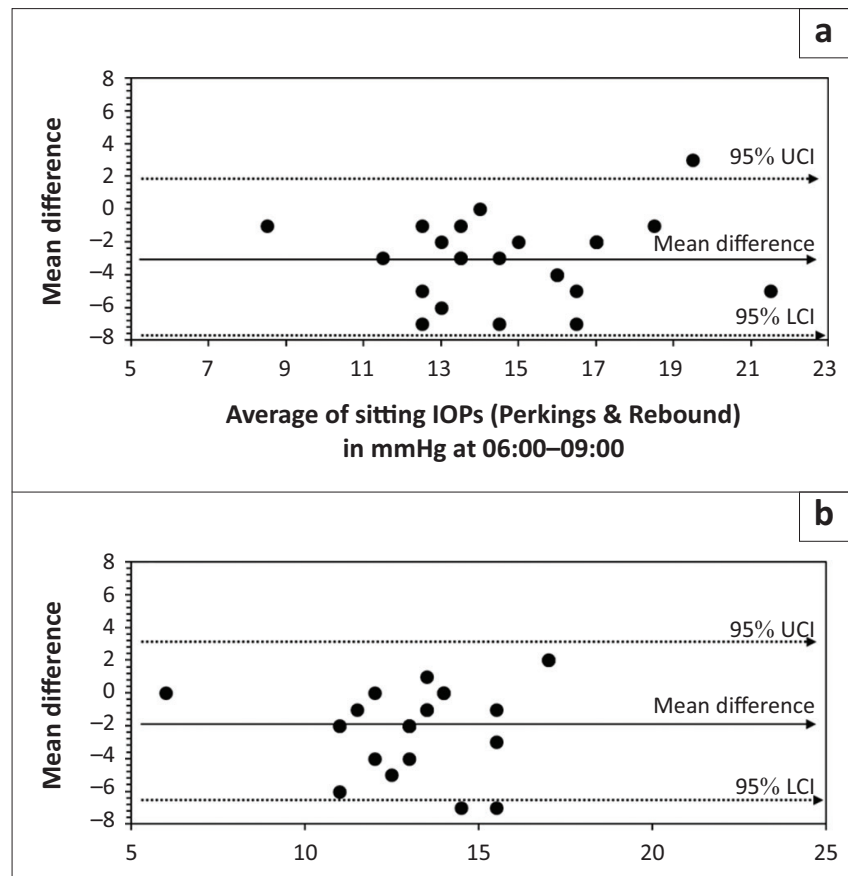

Average of sitting IOPs (Perkings \& Rebound) in $\mathrm{mmHg}$ at 12:00

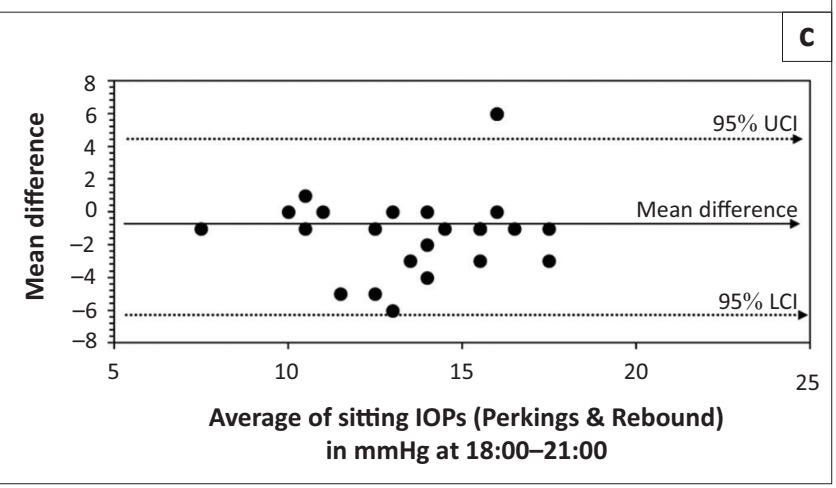

$\mathrm{IOP}$, intraocular pressure; $\mathrm{mmHg}$, millimetre of mercury; $\mathrm{LCl}$, lower confidence interval; $\mathrm{UCI}$ upper confidence interval.

FIGURE 2: Intraocular pressure variations with participants in the sitting position. The Bland and Altman plot of agreement in intraocular pressure from rebound tonometer and Perkins applanation tonometer in the sitting position at different times: (a) 06:00-09:00, (b) 12:00-15:00 and (c) 18:00-21:00. The solid line represents the mean difference, whereas the dotted lines represent the upper and lower limits of agreement.

\section{Discussion}

The study aimed to compare the postural and diurnal IOP variations using the iCare RT and PAT. The findings of the study showed that PAT measured the highest IOP in the morning, with the participants in sitting position, and the lowest IOP in the early evening. The RT recorded higher IOP readings in the mornings and lower readings around midday and early evenings, with the participants in the sitting position. These results indicate that the IOP changes overtime during the day and with the position assumed by the patient during the measurement.

The statistical analysis revealed that IOP is significantly higher when measured in the supine compared to the sitting position. These results support the assertion that posture plays an important role in IOP fluctuation, with IOP being considerably higher when a person is lying down compared to the sitting position. ${ }^{20,21}$ Research $^{4,5}$ suggests that this could partially explain some nocturnal elevations in IOP and, in some instances, possibly contribute to continued glaucomatous damage, despite the measured low IOP during the routine ophthalmic examinations. Advising at risk patients to sleep with their heads elevated by using a pillow could reduce the IOP increase. ${ }^{5}$

In this study, using the PAT with the participants in sitting position, we found the mean IOP to be highest in the morning and lowest in early evening. With the RT, a similar trend of highest readings in the mornings, but lower in the midday and early evenings, was found. This IOP fluctuation with time, as reported by both devices, indicates that the IOP is higher on awakening and lowest in early evening. Similarly, studies $^{22,23}$ have found that IOP peaks in the morning and early afternoon and troughs in the afternoon and at night in patients with primary open-angle glaucoma and normal controls. However, other studies ${ }^{24,25}$ have reported peak IOP readings in the afternoon in patients with secondary openangle glaucoma. The difference in these studies could be because of the different types of diagnosed glaucoma. These results have important clinical implications for the early detection and future diagnosis of glaucoma in patients with normal IOP and also in disease monitoring in patients with visual field deterioration yet with normal IOP readings. For example, it has been reported that the mean IOP, IOP fluctuations, minimal and peak IOP values are predictors of glaucomatous damage. Therefore, diurnal IOP monitoring might potentially be a valuable adjunct to isolated (one-time) IOP measurements during clinic office hour visits as it offers eye care practitioner's information on the circadian IOP rhythm, timing of IOP peaks and magnitude of IOP fluctuations in different glaucoma subtypes. ${ }^{26}$

The findings that both devices returned significantly higher IOPs in the supine position than in the sitting position when measurements were taken in the morning hours (06:00-09:00) are an important consideration to be made when managing the ocular health of a person who is bed-bound, glaucomatous 
or predisposed to glaucoma. Whilst measuring diurnal IOP variation could be difficult, as it involves testing the patient at different times of the day, it provides the eye care practitioner with a better understanding of a patient's IOP range compared to the one-time measurement during clinic hours. The IOP readings obtained using the RT were consistently higher than the PAT particularly in the morning with the participants in the sitting position (Figure 2a, 06:00-09:00), where the mean difference reached $3 \mathrm{mmHg}$. In the supine position, the LoAs reached $15 \mathrm{mmHg}$ for some individuals when taken at midday (Figure $3 b$ ). This finding supports other studies ${ }^{15,27}$ that found a statistically significant difference in IOP with different techniques, suggesting that the two instruments cannot be used interchangeably at any time and any position.

Some of the limitations of this study include the small sample size, which may affect the generalisability of our findings to
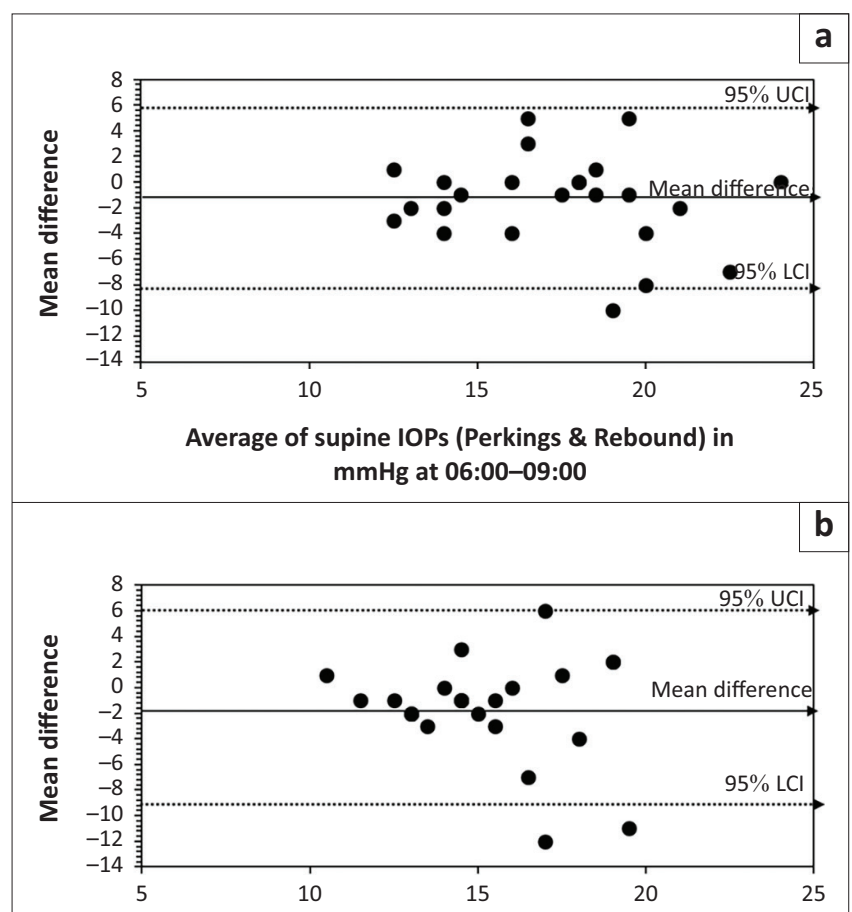

Average of supine IOPs (Perkings \& Rebound) in $\mathrm{mmHg}$ at 12:00

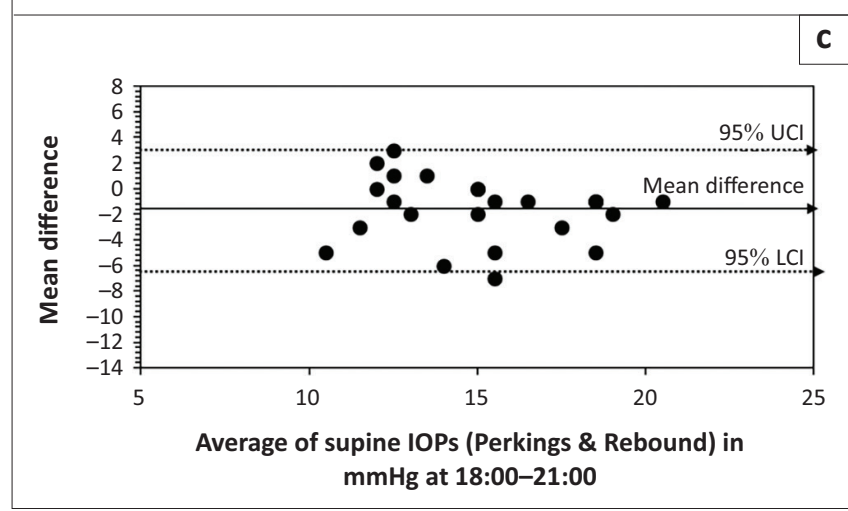

$\mathrm{IOP}$, intraocular pressure; $\mathrm{mmHg}$, millimetre of mercury; $\mathrm{LCl}$, lower confidence interval; $\mathrm{UCI}$ upper confidence interval.

FIGURE 3: Intraocular pressure variations with participants in the supine position. The Bland and Altman plots of agreement in intraocular pressure from iCare and Perkins in the supine position at different times: (a) 06:00-09:00, (b) 12:00-15:00 and (c) 18:00-21:00. The solid line represents the mean difference, whereas the dotted lines represent the upper and lower limits of agreement. the Kenya population; the use of the PAT rather than the GAT which is considered the gold standard compared to other tonometers. Whilst the GAT was not used, as its measurements cannot be obtained in a supine position, a study has shown that the two methods are comparable as they use similar measurement techniques. ${ }^{14}$ Despite these limitations, to the best of the authors' knowledge, this is the first study from Kenya, a developing country setting, providing evidence on the tonometry variations with time and position in this population. Their ease of availability increases the professional competence in the use of these instruments, the two methods being commonly used by clinicians who practise in public-sector hospitals, hence the use of a hospital rather than an eye clinic setting. We found that most studies ${ }^{4,6,28}$ have reported on the postural and diurnal variations using one instrument, and not on instrumentation difference for the same individual, as reported in the current study.

\section{Conclusion}

In summary, significant reductions were observed in IOP values measured in the sitting and supine positions (postural). Similarly, significant reductions were also observed in IOP values measured at different times of the day (diurnal). Diurnal IOP variations were slightly higher when measured by RT compared toPAT. The two techniques cannotbeinterchangeably used for monitoring the IOP readings of patients including those who are bedbound. These findings provide information using local participants to inform clinicians on the diurnal variation in their patients, and this study highlights the significance of these differences when IOP measurements are taken in patients over the age of 40 years.

\section{Acknowledgements}

The authors thank all the patients who participated in this study.

\section{Competing interests}

The authors declare that they have no financial or personal relationships that may have inappropriately influenced them in writing this article.

\section{Authors' contributions}

T.G.C., M.N., N.N.O., I.M., N.J.E-I., U.L.O., F.M.Z., K.A., K.C.O. and K.P.M. contributed to the design and implementation of the research, to the analysis of the results and to the writing of the manuscript.

\section{Funding information}

This research received no specific grant from any funding agency in the public, commercial or not-for-profit sectors.

\section{Data availability}

Data sharing is not applicable to this article. 


\section{Disclaimer}

The views and opinions expressed in this article are those of the authors and do not necessarily reflect the official policy or position of any affiliated agency of the authors.

\section{References}

1. Bourne RRA, Flaxman SR, Braithwaite T, et al. Magnitude, temporal trends, and projections of the global prevalence of blindness and distance and near vision impairment: A systematic review and meta-analysis. Lancet Glob Health 2017;5(9):e888-e897. https://doi.org/10.1016/S2214-109X(17)30293-0

2. Casson RJ, Childlow G, Wood JP, Crowston JG, Golberg I. Definition of glaucoma: Clinical and experimental concepts. Clin Exp Ophthalmol. 2012;40(4):341-349. https://doi.org/10.1111/j.1442-9071.2012.02773.x

3. Krupin T, Liebmann JM, Greenfield DS, Ritch R, Gardiner S, Low-Pressure Glaucoma Study Group. A randomized trial of brimonidine versus timolol in preserving visual function: Results from the low-pressure glaucoma treatment study. Am Ophthalmol. 2011;151(4):671-681. https://doi.org/10.1016/j.ajo.2010.09.026

4. Gautam N, Kaur S, Kaushik S, Raj S, Pandav SS. Postural and diurnal fluctuations in intraocular pressure across the spectrum of glaucoma. $\mathrm{Br} J$ Ophthalmol. 2015;100(4):1-5. https://doi.org/10.1136/bjophthalmol-2015-30686

5. Lee SS, Robinson MR, Weinreb RN. Episcleral venous pressure and the ocula hypotensive effects of topical and intracameral prostaglandin analogs. J Glaucoma. 2019;28(9):846-857. https://doi.org/10.1097/IJG.0000000000001307

6. Arora T, Bali S, Arora V, Wadhawani M, Panda A, Dada T. Diurnal versus office-hour intraocular pressure fluctuation in primary adult-onset glaucoma. J Optom. 2015;8(4):239-243. https://doi.org/10.1016/j.optom.2014.05.005

7. Liu JH. Circadian rhythm of intraocular pressure. J Glaucoma. 1998;7(2):141-147.

8. Wax MB, Camras CB, Fiscella RG, Girkin C, Singh K, Weinreb RN. Emerging perspectives in glaucoma: Optimizing 24-hour control of intraocular pressure. Am J Ophthalmol. 2002;133(6):S1-S10. https://doi.org/10.1016/S0002-9394(02)01459-9

9. Hughes E, Spry P, Diamond J. 24-hour monitoring of intraocular pressure in glaucoma management: A retrospective review. J Glaucoma. 2003;12(3):232-236. https://doi.org/10.1097/00061198-200306000-00009

10. Kiuchi T, Motoyama Y, Oshika T. Relationship of progression of visual field damage to postural changes in intraocular pressure in patients with normal-tension glaucoma. Ophthalmology. 2006;113(12):2150-2155. https://doi.org/10.1016/j ophtha.2006.06.014

11. Huang R, Ge J, Chen G, et al. Four measures of intraocular pressure fluctuation Which correlates most optimally with actual office-hour readings? J Glaucoma. 2015;24(7):550-555. https://doi.org/10.1097/IJG.0000000000000059

12. Bengtsson B, Leske MC, Hyman L, Heijl A, Early Manifest Glaucoma Trial Group. Fluctuation of intraocular pressure and glaucoma progression in The Early Manifest Glaucoma Trial. Ophthalmology. 2007;114(2):205-209. https://doi. org/10.1016/j.ophtha.2006.07.060
13. Ocular Hypertension Treatment Study Group, European Glaucoma Study Group. Validated prediction model for the development of primary open-angle glaucoma in individuals with ocular hypertension. Ophthalmology. 2007;114(1):10-19. in individuals with ocular hypertension. Op
https://doi.org/10.1016/j.ophtha.2006.08.031

14. Arora R, Bellamy H, Austin MW. Applanation tonometry: A comparison of the Perkins handheld and Goldmann slit lamp-mounted methods. Clin Ophthalmol. 2014;8(3):605-610. https://doi.org/10.2147/OPTH.S53544

15. Ting SL, Lim LT, Ooi CY, Rahman MM. Comparison of iCare rebound tonometer and Perkins Applanation Tonometer in community eye screening. Asia Pac Ophthalmol (Phila). 2019;8(3):229-232. https://doi.org/10.22608/APO.2018433

16. Abraham LM, Epasinghe NCR, Selva D, Casson R. Comparison of the iCare rebound tonometer with the Goldmann applanation tonometer by experienced and inexperienced tonometrists. Eye. 2008;22(4):503-506. https://doi.org/10.1038/ sj.eye. 6702669

17. Rehnman JB, Martin L. Comparison of rebound and applanation tonometry in the management of patients treated for glaucoma or ocular hypertension. Ophtha Physiol Opt. 2008;28(4):382-386. https://doi.org/10.1111/j.1475-1313.2008.00571.x

18. Heijl A. Glaucoma treatment: By the highest level of evidence. Lancet. 2015;385(9975):1264-1266. https://doi.org/10.1016/S0140-6736(14)62347-3

19. Sit AJ. Intraocular pressure variations: Causes and clinical significance. Can J Ophthalmol. 2014;9(6):484-488. https://doi.org/10.1016/j.jcjo.2014.07.008

20. Malihi M, Sit AJ. Effect of head and body position on intraocular pressure. J Ophthalmol. 2012;119(5):987-991. https://doi.org/10.1016/j.ophtha.2011. 11.024

21. De Bernardo M, Borrelli M, Cembalo G, Rosa N. Intraocular pressure measurements in standing position with a rebound Tonometer. Medicina (Kaunas). 2019;55(10):701. https://doi.org/10.3390/medicina55100701

22. Arora T, Bali S, Arora V, Wadhawani M, Panda A, Dada T. Diurnal versus office-hour intraocular pressure fluctuation in primary adult-onset glaucoma. J Optom. 2015;8(4):239-243. https://doi.org/10.1016/j.optom.2014.05.005

23. Kim SH, Lee EJ, Han JC, Sohn SW, Rhee T, Kee C. The effect of diurnal fluctuation in intraocular pressure on the evaluation of risk factors of progression in normal tension glaucoma. PLoS One. 2016;11(10):Article ID e0164876. https://doi org/10.1371/journal.pone.0164876

24. Jonas JB, Budde WM, Stroux A, Oberacher-Velten IM, Junemann A. Diurnal intraocular pressure profiles in chronic open-angle glaucoma. Asia Pac Ophthalmol. 2012;1(2):84-87. https://doi.org/10.1097/APO.0b013e31823e4cb0

25. Sit AJ, Pruet CM. Personalizing intra ocular pressure; target intraocular pressure in the setting of a 24-hour intraocular pressure monitoring. Asia Pac J Ophthalmol (Phila). 2016;5(1):17-22. https://doi.org/10.1097/APO.0000000000000178

26. $\mathrm{Ho} \mathrm{CH}$, Wong JKW. Role of 24-hour intraocular pressure monitoring in glaucoma management. J Ophthalmol. 2019; Article ID 3632197, 13 pages. https://doi. org/10.1155/2019/3632197

27. Asrani S, Zeimer R, Wilensky J, Gieser D, Vitale S, Lindenmuth K. Large diurnal fluctuations in intraocular pressure are an independent risk factor in patients with glaucoma. J Glaucoma. 2000;9(2):134-142. https://doi.org/10.1097/00061198200004000-00002

28. Lam A, Wu YF, Wong LY, Ho NL. IOP variations from sitting to supine postures determined by rebound tonometer. J Optom. 2013;6(2):95-100. https://doi. org/10.1016/j.optom.2012.12.002 